\title{
Epidemiology of diabetes mellitus, pre- diabetes, undiagnosed and uncontrolled diabetes in Central Iran: results from Yazd health study
}

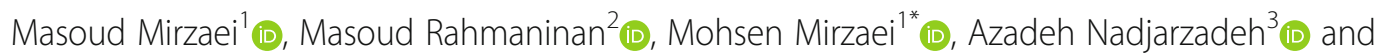
Abbas Ali Dehghani tafti ${ }^{4}$ (I)

\begin{abstract}
Background: Over the past few decades, the prevalence of Diabetes Mellitus (DM) has risen rapidly in Iran and other low and middle-income countries. We investigated the prevalence of DM, pre-diabetes, undiagnosed and uncontrolled diabetes and its relationship with some associated socioeconomic factors in the Yazd Greater Area in Iran.

Methods: Yazd Health Study is a longitudinal study conducted to determine the prevalence of non-communicable disease and related risk factors. In a two-step cluster sampling, 10,000 adults aged 20-69years (200 clusters) were selected. In the recruitment phase, DM was considered if the patients had been either diagnosed DM by a physician or had fasting blood glucose $\geq 126 \mathrm{mg} / \mathrm{dL}$. Chi square test was used for categorical variables to evaluate the differences and logistic regression model was applied to determine the predictors of diabetes.. $P$-value $<0.05$ considered statistically significant.

Results: Of the 9965 individuals recruited, the crude self-reported prevalence of DM was 14.1\% (95\% Cl: 13.4-14.7). The prevalence was higher in women than men (15.6 vs.12.4\%), significantly. The age-standardized prevalence of DM was 8\%. The prevalence was 14.9\% in Yazd local people and $8.6 \%$ in those residents migrated from other provinces $(P<0.0001)$. We showed a significant association between DM prevalence and age, education, marital status, unemployment, insurance status, and positive family history $(P<0.0001)$. The prevalence of DM diagnosed by phycisians was $16.1 \%$ in participants (age-standardized prevalence: $8.3 \%$ ). The subset analysis showed that $4.8 \%$ of patients were not aware of their disease. The prevalence of pre-diabetes was $25.8 \%$. Of those with diabetes, $58.3 \%$ were not adequately controlled, which is not statistically significant with socio-economic status.

Conclusion: The current study showed a high prevalence of DM in Yazd Greater Area which is closely related to some socio-demographic factors. The high prevalence of pre-diabetes is alarming. Effective strategies for DM prevention should be introduced. The majority of people with diabetes are aware, but half of them are not controlled. The ineffective care plan currently in use, should be reviewed. Patients needs to be encouraged to improve their lifestyle. Active follow-up of patients is recommended to ensure continuity of care.
\end{abstract}

Keywords: Diabetes, Prevalence, Risk factors, Socio-economic, Iran

\footnotetext{
* Correspondence: drmmirzaei@ssu.ac.ir

${ }^{1}$ Yazd Cardiovascular Research Center, Shahid Sadoughi University of Medical

Sciences, Jomhuri Blvd., Afshar Hospital, Yazd, Iran

Full list of author information is available at the end of the article
}

(c) The Author(s). 2020 Open Access This article is distributed under the terms of the Creative Commons Attribution 4.0 International License (http://creativecommons.org/licenses/by/4.0/), which permits unrestricted use, distribution, and reproduction in any medium, provided you give appropriate credit to the original author(s) and the source, provide a link to the Creative Commons license, and indicate if changes were made. The Creative Commons Public Domain Dedication waiver (http://creativecommons.org/publicdomain/zero/1.0/) applies to the data made available in this article, unless otherwise stated. 


\section{Background}

Diabetes mellitus (DM) is a major public health problem that is determined with impaired carbohydrate metabolism, protein, and fat due to unstable insulin secretion, insulin resistance secretion, or both [1]. With an $8.5 \%$ global prevalence of diabetes in 2014; various estimates suggest that the number of affected people will be risen from 422 million to 642 million in the world by 2040 [2, 3].

DM and its complications are among the most important causes of mortality.

Between 1990 and 2010; the rank of the disease has moved from 15 to 9, which corresponds to a $92.7 \%$ increase in the burden during the period [4]. Over the past decade, the prevalence of diabetes has risen rapidly due to an increase in the average age of the community, hereditary background, unhealthy dietary habits, sedentary lifestyle and increased obesity in line with the growth of urbanization $[5,6]$.

The prevalence of diabetes is estimated to be $8.5 \%$ in adults aged over 18 years in 2014 which has increased significantly over the past three decades, especially in low and middle-income countries [2]. In the Eastern Mediterranean Region (EMRO), the average prevalence of diabetes in adult population was $13.7 \%$ in 2014, which is the highest prevalence compared to other WHO regions [2].

In Iran, the prevalence of diabetes in adults aged 2570 years was reported $11.9 \%$ (2011) which shows an increase of $35 \%$ compared to 2005 . It is estimated that in the year 2030 nearly 9.2 million Iranians likely to have diabetes [7]. Many people with diabetes are unaware of their complications due to uncontrolled blood glucose level [8]. A significant percentage of patients are unaware of their illness (from $30 \%$ in Iran to $86 \%$ in Tunisia in the Middle East and from 24.1 to $75.1 \%$ in other parts of the world) $[9,10]$. Delay in the diagnosis of DM increases the cost of management and reduces the prognosis of the disease [11].

Yazd, a world heritage city located in the center of Iran, has one of the highest recorded prevalence of DM in Iran [12]. The prevalence of DM in Yazd province in the population over 30 years old was reported from $13.8 \%$ in 1998 to $16.3 \%$ in 2012 [13, 14]. Recent studies have reported the prevalence of the DM in 40-80-years old group 24.5\% [15]. However, no comprehensive, current and representative data is available for this prevalent disease in Yazd. This study was undertaken to estimate; a) the prevalence of type 2 diabetes (T2DM) and pre-diabetes in the adult population of Yazd, b) to estimate adult un-awareness of diabetes, c) to assess the quality of care of patients in controlling the disease and its complications and d) to estimate the extent that prevalence of T2DM is affected by socioeconomic factors including gender, age group, education, ethnicity and immigration, marital status, employment and health insurance.

\section{Methods}

Setting, study design and data collection

Yazd Health Study (YaHS) is a prospective cohort study conducted to determine the prevalence of noncommunicable disease and related risk factors in Yazd Greater Area. Yazd is a World Heritage City recognized by UNESCO located in the center of Iran. The sampling procedure of the YaHS study has been published elsewhere [16]. Briefly, 10,000 residents of Yazd city at the age of 20 to 69 years were selected using cluster random sampling method. At first, 200 clusters were randomly selected based on the zip code. Then, each cluster of 50 samples was divided into the following subgroups: 25 men and 25 women; five people in each age group. Each group consists of 10 people in the age group of 20-29, 30-39, 40-49, 50-59 and 60-69 years old. Inclusion criteria were ages $20-69$ years at the time of the interview and completed informed consent to participate in the study (94.9\% response rate) (Fig. 1).

The interviewers went to the houses of the selected individuals and coordinate for a meeting at their home to complete the questionnaire. A team of experts suggested and approved questions. The face validity was guaranteed by the panel and the Cronbach's alpha of the questionnaire was $0.89 \%$ at the pilot stage. That who was guests and residing elsewhere was excluded from the study. Then, they were invited to go to the laboratory to perform a blood test. To assess the potential impact of individual-level socioeconomic on diabetes, self-reported information on education level, job status, health insurance, marital status, migration, and religion were recorded. Upon completion of the interview, an invitation card was sent to each participant to attend the laboratory before $9 \mathrm{am}$ and after $10 \mathrm{~h}$ of fasting. In the laboratory, five $\mathrm{ml}$ fresh blood was taken from each participant; collected in an oxalate tube and centrifuged at standard time for biochemistry tests using calibrated instruments and biochemistry kits. All measurements were performed on a standard laboratory protocol using Pars Azmoon kits and Ciba Corning (Ciba Corp. Switzerland) auto-analyzer. Based on the study protocol, the team repeatedly reviews and measures every five years to determine longitudinal information on risk factors and health changes.estimates of prevalence were reported according to baseline data (recruitment phase) here. 3810 interviewees agreed to participate in laboratory sampling (about $40 \%$ response rate). Baseline Characteristics of the laboratory data group and those, who had no lab data was compared in Table 1. 


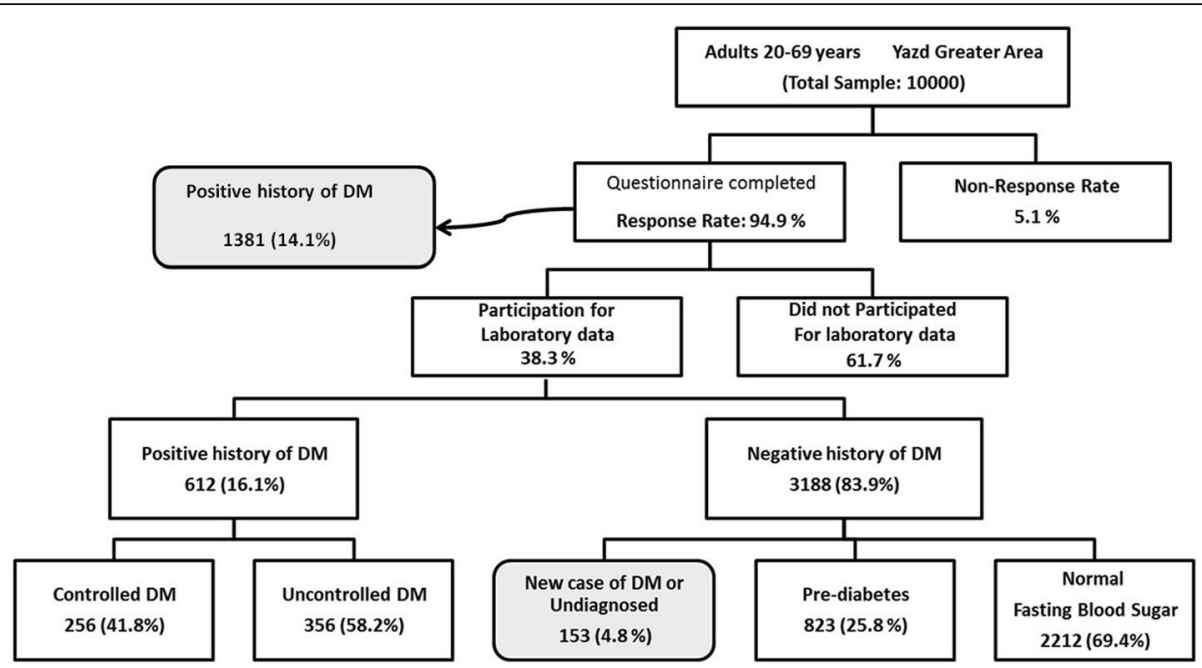

Fig. 1 Flow diagram of participants in Yazd Health Study, who respond to questionnaires and agreed for fasting blood glucose sampling. (2014-2015)

\section{Diagnosis of diabetes}

The following criteria were used to consider a person diabetics and the prevalence was calculated accordingly. History of DM was recorded by practitioner diagnosis over a lifetime according to patients' interviews (self-reported). DM was defined as fasting plasma glucose $(F P G) \geq 126 \mathrm{mg} / \mathrm{dl}(7.0 \mathrm{mmol} / \mathrm{L})$ by American Diabetes Association (ADA). Undiagnosed diabetes was defined as not having self-reported diabetes but having a fasting plasma glucose (FPG) $\geq 126 \mathrm{mg} / \mathrm{dl}$ in the blood test. Control of DM and pre-diabetes were defined as an FPG lower than $126 \mathrm{mg} / \mathrm{dl}$ and between 100 and $125.9 \mathrm{mg} / \mathrm{dl}$ (5.6-6.9 $\mathrm{mmol} / \mathrm{L})$, respectively [17-19].

\section{Statistical analysis}

Yazd population in 2011 were used for direct sex and age-standardization. Categorical variables were presented as frequencies and percentages and the prevalence of DM control was reported as proportions. Chi-square test was used for categorical variables to analyze the differences in demographics across the groups. Multivariate logistic regression models were applied to determine the predictors of diabetes (diagnosed, undiagnosed and controlled) and pre-diabetes. Adjusted odds ratios were reported. To neutralize the effect of non-response bias, we weighted the data of the participants, who agreed for blood tests, in the analysis. Weighting was done for gender and age groups, weights were calculated by dividing the population percentage by the subsample percentage. All statistical analyses were performed using SPSS version 16.0 software. A p-value less than 0.05 was considered statistically significant.

\section{Results}

Of the 9965 individuals recruited, 1378 reported having DM, a crude prevalence of $14.1 \%(95 \% \mathrm{CI}=13.4-14.7)$ which is more common in women than men $(15.6 \%$ vs. $12.4 \%)$. The prevalence of diabetes increases with age. (33.8\% at $60-69$ years, compared to $1.3 \%$ at $20-29$ years). The estimation of age-standardized prevalence of DM was calculated by sex. The standardized prevalence of diabetes in the study population (20-69) was estimated at $8 \%(8.9 \%$ in women \& $7.0 \%$ in men), which increases with age and reaches $18 \%$ in age $40-69$ yeras $(20.4 \%$ in men and $16 \%$ in women). Figure 1 presents the flowchart of the study and the rate of participation. It shows a summary of the most important results.

Stratified by migration status, the prevalence of DM was $14.9 \%$ (95\% CI $=13.9-15.5)$ in Yazd local people and 8.6\% (95\% CI $=7.0-10.1)$ in those migrated from other provinces. A difference was found between the prevalence of diabetes in different education groups $(P<$ 0.001). The illiterate/elementary adults had the highest history diabetes(26.4\%), and those with university education reported the lowest prevalence $(4.7 \%)$. The prevalence of diabetes was higher in individuals who had health insurance (14.4\%) compared to uninsured (7.2\%). Table 2 shows the prevalence of diabetes according to socio-economic determinants. Self-reported DM in Zoroastrians, a religious minority, was $11.2 \%$ (95\% CI = 7.0-15.2) which was not significantly different from the majority Muslim population.

Of the total population, $1.7 \%$ (8.0\% of DM patients) reported having diabetes mellitus for less than one year. According to the results, it is estimated that the incidence of disease was just about $1.1 \%$ in this age group. Oral medications or insulin in $86.8 \%$ of individuals with 
Table 1 Baseline Characteristics of the laboratory data Group and those, who had no lab data

\begin{tabular}{|c|c|c|c|c|}
\hline \multirow[t]{2}{*}{ Variable } & \multicolumn{2}{|c|}{ Laboratory Exam } & \multirow[t]{2}{*}{ Total } & \multirow[t]{2}{*}{$P$ Value } \\
\hline & Participant & Non-participant & & \\
\hline Total & $3810(38.4 \%)$ & 6100(61.6\%) & & \\
\hline \multicolumn{5}{|l|}{ Gender } \\
\hline Male & $1766(46.4 \%)$ & 3155 (51.7\%) & 4921 & \multirow[t]{2}{*}{$<0.0001$} \\
\hline Female & $2044(53.6 \%)$ & $2945(48.3 \%)$ & 4989 & \\
\hline \multicolumn{5}{|l|}{ Age group } \\
\hline $20-29$ & $566(14.9 \%)$ & 1397 (22.9\%) & 1963 & \multirow[t]{5}{*}{$<0.0001$} \\
\hline $30-39$ & $691(18.2 \%)$ & 1334 (21.8\%) & 2025 & \\
\hline $40-49$ & $853(22.4 \%)$ & 1196 (19.6\%) & 2049 & \\
\hline $50-59$ & $863(22.7 \%)($ & $1106(18.1 \%)$ & 1969 & \\
\hline $60-69$ & $834(21.9 \%)$ & $1073(17.6 \%)$ & 1907 & \\
\hline \multicolumn{5}{|l|}{ Marital status } \\
\hline Married & $3321(87.2 \%)$ & 5109 (83.6\%) & 8430 & \multirow[t]{3}{*}{$<0.0001$} \\
\hline Single & $295(7.7 \%)$ & $759(12.4 \%)$ & 1054 & \\
\hline Widowed/Divorced & $192(5.0 \%)$ & $243(4.0 \%)$ & 435 & \\
\hline \multicolumn{5}{|l|}{ Insurance } \\
\hline Insured & 3585 (95.4\%) & 5676 (93.9\%) & 9261 & \multirow[t]{2}{*}{0.001} \\
\hline Not insured & $171(4.6 \%)$ & $366(6.1 \%)$ & 537 & \\
\hline \multicolumn{5}{|l|}{ Job-status } \\
\hline Employed & 1379 (36.6\%) & $2547(42.3 \%)$ & 3926 & \multirow[t]{3}{*}{$<0.0001$} \\
\hline Unemployed & $1585(42.1 \%)$ & 2240 (37.2\%) & 3825 & \\
\hline Housewife & $802(21.3 \%)$ & $1237(20.5 \%)$ & 2039 & \\
\hline \multicolumn{5}{|l|}{ Education } \\
\hline Primary school and less & 1118 (29.5\%) & 1469 (24.2\%) & 2587 & \multirow[t]{5}{*}{$<0.0001$} \\
\hline High school & $1136(30.3 \%)$ & $1666(27.4 \%)$ & 2802 & \\
\hline Diploma\& Graduate diploma & $1027(27.1 \%)$ & 1905 (31.3\%) & 2932 & \\
\hline BSC & $431(11.4 \%)$ & $860(14.1 \%)$ & 1291 & \\
\hline MSc. and Doctorate & $73(1.9 \%)$ & $181(3.0 \%)$ & 254 & \\
\hline
\end{tabular}

DM were used to control the disease. Regular use of the medications has been reported in $84.1 \%$ of patients $(95 \%$ CI: $80.8-86.9$ ). Over the last year, $91 \%$ of the patients referred to a physician, $67.1 \%$ had been visited by a specialist physician in the same period. Table 3 shows the details of DM management in Yazd population.

The results of the FPG of 3810 people (approximately $40 \%$ of the participants) show that $4.0 \%$ (95\% CI: 3.44.7) of people, were not aware of DM which was increased with age $(p$-value $<0.0001)$. Table 4 shows frequency of DM, pre-diabetes, undiagnosed DM and uncontrolled DM in Yazd adult population, who participated in the study and gave blood for tests. All prevalence estimates were weighted on the basis of the age and sex variables, that are under- or overrepresented in the subsample.

Undiagnosed diabetes was more common in men than in women $(4.0 \%$ vs. $3.7 \%)$. Blood glucose was not controlled in $58.3 \%$ (95\% CI $=54.2-62.1)$ of individuals with DM, which is not statistically significant between different age-groups and across sexes (p-value >0.05). Prevalence of pre-diabetes was $25.8 \%$ (95\% CI: $24.3-$ 27.3) in adults. The logistic regression analysis showed that DM was higher among the women (OR: 1.4, 95\% CI: (1.1-1.7)), the eldest age group (OR: 25.0). being male, younger and educated were protective factors of DM but unemployment and widow/divorced adult were high risks for it. $(p>0.05)$. In this model, there was no significant relationship between sex, education, marital status and health insurance with undiagnosed or control of DM in patients. However, higher education is a protective factor for pre-diabetes and diabetes (Table 5).

\section{Discussion}

The present study is a descriptive analysis of diabetes status in Yazd Greater Area which addressed the 
Table 2 Socioeconomic factors associated with self-reported diabetes mellitus in Yazd greater area. 2014-2015

\begin{tabular}{|c|c|c|c|}
\hline \multirow{3}{*}{ Gender } & \multicolumn{2}{|c|}{ A positive history of diabetes mellitus } & \multirow[t]{2}{*}{$p$-value } \\
\hline & \multirow[t]{2}{*}{ Num. } & \multirow[t]{2}{*}{ Percent (95\% Confidence Interval) } & \\
\hline & & & \\
\hline & 606 & $12.4(11.5-13.3)$ & $<0.0001$ \\
\hline Women & 772 & $15.6(14.6-16.6)$ & \\
\hline Total & 1378 & $14.1(13.4-14.7)$ & \\
\hline \multicolumn{4}{|l|}{ Age group } \\
\hline $20-29$ & 26 & $1.3(0.8-1.8)$ & $<0.0001$ \\
\hline $30-39$ & 62 & $3.1(2.3-3.8)$ & \\
\hline $40-49$ & 182 & $8.9(7.7-10.2)$ & \\
\hline $50-59$ & 472 & $24.1(22.2-26.0)$ & \\
\hline $60-69$ & 644 & $33.8(31.7-35.9)$ & \\
\hline \multicolumn{4}{|l|}{ Education } \\
\hline Primary school and less & 680 & $26.4(24.7-28.1)$ & $<0.0001$ \\
\hline High school & 412 & $14.8(13.5-16.1)$ & \\
\hline Diploma and graduate diploma & 220 & $7.5(6.6-8.5)$ & \\
\hline $\mathrm{BSC}$ & 60 & $4.7(3.5-5.8)$ & \\
\hline MSc. and doctorate & 12 & $4.7(21 .-7.3)$ & \\
\hline \multicolumn{4}{|c|}{ Positive family history of diabetes mellitus } \\
\hline Yes & 908 & $24.5(23.1-25.9)$ & $<0.0001$ \\
\hline No & 460 & $8.1(7.4-8.9)$ & \\
\hline \multicolumn{4}{|l|}{ Employment } \\
\hline Employed & 307 & $7.9(7.0-8.7)$ & $<0.0001$ \\
\hline Unemployed & 627 & $16.5(15.3-17.7)$ & \\
\hline Housewife & 424 & $20.9(19.1-22.7)$ & \\
\hline \multicolumn{4}{|l|}{ Health insurance } \\
\hline Not insured & 38 & $7.2(4.9-9.4)$ & $<0.0001$ \\
\hline Iran Health Insurance Organization & 275 & $19.8(17.7-21.9)$ & \\
\hline Social Security Organization & 919 & $13.3(12.5-14.0)$ & \\
\hline General health insurance & 32 & $14.8(10.0-19.6)$ & \\
\hline Others & 102 & $15.0(12.3-17.7)$ & \\
\hline \multicolumn{4}{|l|}{ Migration status } \\
\hline Native & 1100 & $14.9(14.0-15.7)$ & $<0.0001$ \\
\hline From within the province & 143 & $15.3(13.0-17.6)$ & \\
\hline From other provinces & 108 & $8.6(7.0-10.1)$ & \\
\hline From overseas & 28 & $13.1(8.6-17.7)$ & \\
\hline \multicolumn{4}{|l|}{ Marriage status } \\
\hline Married & 1229 & $14.7(13.9-15.4)$ & $<0.0001$ \\
\hline Single & 24 & $2.3(1.3-3.2)$ & \\
\hline Widowed & 132 & $34.9(30.1-39.7)$ & \\
\hline Divorced & 2 & $3.6(0.0-8.7)$ & \\
\hline \multicolumn{4}{|l|}{ Religion } \\
\hline Muslim & 1346 & $14.2(13.5-14.9)$ & 0.216 \\
\hline Zoroastrian & 26 & $11.1(7-15.2)$ & \\
\hline
\end{tabular}


Table 3 Duration of self-reported diabetes mellitus and diabetes care behaviors in Yazd by sex 2014-2015

\begin{tabular}{|c|c|c|c|c|c|c|c|}
\hline & \multicolumn{4}{|c|}{ Gender } & \multirow{2}{*}{\multicolumn{2}{|c|}{ Total }} & \multirow[t]{3}{*}{$P$-value } \\
\hline & \multicolumn{2}{|l|}{ Male } & \multicolumn{2}{|c|}{ Female } & & & \\
\hline & Num. & Percent $(95 \% \mathrm{Cl})$ & Num. & Percent $(95 \% \mathrm{Cl})$ & Num. & Percent $(95 \% \mathrm{Cl})$ & \\
\hline \multicolumn{8}{|c|}{ Duration of diabetes mellitus (years) } \\
\hline$<1$ & 39 & $6.6(4.9-8.9)$ & 68 & $9.1(7.3-11.4)$ & 107 & $8.0(6.7-9.6)$ & \multirow[t]{5}{*}{0.110} \\
\hline $1-2$ & 92 & $15.6(12.9-18.7)$ & 138 & $18.5(15.9-21.5)$ & 230 & $17.2(15.3-19.4)$ & \\
\hline $3-4$ & 102 & $17.3(14.4-20.5)$ & 139 & $18.7(16.0-21.6)$ & 241 & $18.1(16.1-20.2)$ & \\
\hline $5-6$ & 101 & $17.1(14.3-20.4)$ & 108 & $14.5(12.2-17.7)$ & 209 & $15.7(13.8-17.7)$ & \\
\hline$=>7$ & 258 & $43.4(39.4-47.4)$ & 744 & $39.1(35.7-42.7)$ & 547 & $41.0(38.4-43.7)$ & \\
\hline \multicolumn{8}{|l|}{ Type of medication } \\
\hline Food regimen & 19 & $3.8(2.5-5.9)$ & 33 & $5.6(4.0-7.8)$ & 52 & $4.8(3.7-6.3)$ & \multirow[t]{5}{*}{0.017} \\
\hline Traditional & 7 & $1.4(0.6-2.9)$ & 22 & $3.8(2.5-5.6)$ & 29 & $2.7(1.9-3.8)$ & \\
\hline Oral drug & 335 & $67.8(63.6-71.8)$ & 393 & $67.2(63.3-70.9)$ & 728 & $67.5(64.6-70.2)$ & \\
\hline Insulin & 96 & $19.4(16.2-23.1)$ & 112 & $19.1(16.2-22.5)$ & 208 & $19.3(17.0-21.7)$ & \\
\hline I don't take medication & 37 & $7.5(5.5-10.1)$ & 25 & $4.3(2.9-6.2)$ & 62 & $5.7(4.5-7.3)$ & \\
\hline \multicolumn{8}{|c|}{ Do you take medication regularly for diabetes? } \\
\hline Yes & 456 & $84.1(80.8-86.9)$ & 561 & $84.0(81.0-86.6)$ & 1017 & $84.0(81.9-86.0)$ & \multirow[t]{2}{*}{0.943} \\
\hline No & 86 & $15.9(13.0-19.2)$ & 107 & $16.0(13.4-18.9)$ & 193 & $16.0(14.0-18.1)$ & \\
\hline \multicolumn{8}{|c|}{ When was the last time you visited your doctor? } \\
\hline $3-6$ months & 415 & $76.1(72.2-79.5)$ & 525 & $76.3(72.9-79.3)$ & 940 & $76.2(73.8-78.5)$ & \multirow[t]{5}{*}{0.789} \\
\hline 7-12 months & 78 & $14.3(11.6-17.5)$ & 105 & $15.3(12.8-18.1)$ & 183 & $14.8(13.0-16.9)$ & \\
\hline $2-3$ years & 32 & $5.9(4.2-8.2)$ & 38 & $5.5(4.0-7.5)$ & 70 & $5.7(4.5-7.1)$ & \\
\hline $4-10$ years & 8 & $1.5(0.7-2.9)$ & 11 & $1.6(0.9-2.8)$ & 19 & $1.5(0.9-2.4)$ & \\
\hline$=>10$ years & 12 & $2.2(1.3-3.8)$ & 9 & $1.3(0.7-2.5)$ & 21 & $1.7(0.1-2.6)$ & \\
\hline \multicolumn{8}{|c|}{ Which specialist doctor did you visit? } \\
\hline General physician & 183 & $31.8(28.1-35.7)$ & 244 & $33.7(30.3-37.2)$ & 427 & $32.8(30.3-35.5)$ & \multirow[t]{3}{*}{0.604} \\
\hline Internal medicine & 273 & $47.5(43.4-51.6)$ & 324 & $44.7(41.1-48.3)$ & 597 & $45.9(43.2-48.6)$ & \\
\hline Endocrinologist & 119 & $20.7(17.6-24.2)$ & 157 & $21.7(18.8-24.8)$ & 276 & $21.2(19.1-23.5)$ & \\
\hline
\end{tabular}

frequency of DM and pre-diabetes across different agegroups, socioeconomic status, type of treatments received and awareness of the disease. According to age group distribution, Yazd has a young population structure (mean age 28.9 years), the age-standardized prevalence of diabetes estimated lower than the crude self- reported prevalence in Yazd Health Study (8\% vs. $14.1 \%)$. It is expected, with an increase in the elderly population,DM prevalence increases in the future.

Our finding showed that based on FPG, 17.2\% (95\% $\mathrm{CI}=16.4-18.0)$ of people older than 30-year-old have DM, more in women than men. Afkhami et al. in 1998

Table 4 Prevalence of diabetes mellitus, Pre-diabetes, undiagnosed \& uncontrolled DM in Yazd greater area (2014-2015)

\begin{tabular}{llll}
\hline Diabetes status & \multicolumn{2}{c}{ participants, who agreed for the blood sample } & $\begin{array}{c}\text { Adjusted } \\
\text { weighted } \\
\text { estimation }\end{array}$ \\
\cline { 2 - 4 } & Unweight & Weighted & $17.7 \%(16.9-18.4)$ \\
\hline Pre-diabetes & $21.7 \%(20.4-23.1)$ & $20.7 \%(19.5-22.1)$ & $10.9 \%(10.3-11.5)$ \\
Total DM ${ }^{\text {b }}$ & $20.1 \%(18.8-21.4)$ & $18.1 \%(16.9-19.3)$ & $8.3 \%(7.8-8.8)$ \\
$\quad$ Self- reported DM & $16.1 \%(14.9-17.3)$ & $14.4 \%(13.4-15.6)$ & $2.6 \%(2.3-2.9)$ \\
$\quad$ Undiagnosed DM & $4.0 \%(3.4-4.7)$ & $3.7 \%(3.1-4.3)$ & $47.1 \%(44.2-50.1)$ \\
Uncontrolled DM & $58.2 \%(54.2-62.0)$ & $58.1 \%(54.0-62.2)$ & \\
\hline
\end{tabular}

age and sex standardized by census data

${ }^{\mathrm{b}}$ Sum of self-reported diabetes and undiagnosed 
Table 5 Socioeconomic factors related with prevalence of diabetes, pre-diabetes, undiagnosed and uncontrolled diabetes mellitus in Yazd

\begin{tabular}{|c|c|c|c|c|c|}
\hline & Prevalence of DM ${ }^{a}$ & Prevalence of DM ${ }^{b}$ & Undiagnosed $\mathrm{DM}^{\mathrm{b}}$ & Uncontrolled DM ${ }^{\mathrm{b}}$ & Pre-diabetes $^{b}$ \\
\hline & OR $(95 \% \mathrm{Cl})$ & OR $(95 \% \mathrm{Cl})$ & OR $(95 \% \mathrm{Cl})$ & OR $(95 \% \mathrm{Cl})$ & OR $(95 \% \mathrm{Cl})$ \\
\hline \multicolumn{6}{|l|}{ Gender } \\
\hline Male & Ref. & Ref. & Ref. & Ref. & Ref. \\
\hline Female & $1.4(1.1-1.7)$ & $1.2(0.9-1.6)$ & $0.7(0.4-1.3)$ & $1.1(0.6-1.8)$ & $1.2(0.9-1.5)$ \\
\hline \multicolumn{6}{|l|}{ Age groups } \\
\hline $20-29$ & Ref. & Ref. & Ref. & Ref. & Ref. \\
\hline $30-39$ & $2.2(1.3-3.6)$ & $2.4(1.0-5.8)$ & $0.8(0.3-2.3)$ & $1.8(0.2-13.3)$ & $1.3(0.9-1.9)$ \\
\hline $40-49$ & $5.6(3.5-9.0)$ & $6.4(2.8-14.7)$ & $2.1(0.8-5.5)$ & $2.0(0.3-13.3)$ & $2.8(2.0-4.1)$ \\
\hline $50-59$ & $17.3(11.0-27.3)$ & $18.7(8.3-42.2)$ & $3.7(1.4-9.5)$ & $2.0(0.3-12.8)$ & $4.3(3.0-6.2)$ \\
\hline $60-69$ & $25.0(15.8-39.7)$ & $25.3(11.1-57.4)$ & $4.8(1.8-12.5)$ & $2.1(0.3-13.1)$ & $4.39(3.0-6.5)$ \\
\hline \multicolumn{6}{|l|}{ Education } \\
\hline Primary school \& less & Ref. & Ref. & Ref. & Ref. & Ref. \\
\hline High school & $0.9(0.8-1.1)$ & $0.9(0.7-1.1)$ & $1.0(0.7-1.5)$ & $0.8(0.5-1.2)$ & $0.8(0.6-1.0)$ \\
\hline Diploma \&Graduate Diploma & $0.7(0.5-0.8)$ & $0.8(0.6-1.0)$ & $0.5(0.3-0.9)$ & $1.0(0.6-1.6)$ & $0.9(0.7-1.2)$ \\
\hline BSc,MSc.Doctorate & $0.6(0.4-0.7)$ & $0.5(0.3-0.8)$ & $0.5(0.2-1.1)$ & $0.5(0.2-1.3)$ & $0.6(0.5-0.9)$ \\
\hline \multicolumn{6}{|l|}{ Health insurance } \\
\hline No & Ref. & Ref. & Ref. & Ref. & Ref. \\
\hline Yes & $1.4(0.9-2.0)$ & $0.8(0.5-1.3)$ & $1.7(0.5-5.5)$ & $0.9(0.3-2.2)$ & $1.6(1.0-2.7)$ \\
\hline \multicolumn{6}{|l|}{ Employment } \\
\hline Employed & Ref. & Ref. & Ref. & Ref. & Ref. \\
\hline Housewife & $1.0(0.8-1.3)$ & $1.0(0.7-1.4)$ & $1.0(0.5-1.9)$ & $0.7(0.4-1.3)$ & $0.9(0.7-1.2)$ \\
\hline Unemployed & $1.4(1.2-1.7)$ & $1.5(1.1-1.9)$ & $0.80(0.5-1.3)$ & $0.9(0.5-1.4)$ & $0.7(0.6-0.9)$ \\
\hline \multicolumn{6}{|l|}{ Marriage status } \\
\hline Married & Ref. & Ref. & Ref. & Ref. & Ref. \\
\hline Single & $0.8(0.5-1.4)$ & $0.8(0.3-1.7)$ & $0.4(0.1-1.9)$ & $0.3(0.1-1.9)$ & $1.2(0.8-1.8)$ \\
\hline Widow/divorced & $1.3(1.0-1.6)$ & $1.3(0.9-1.8)$ & $1.3(0.6-2.5)$ & $1.4(0.8-2.5)$ & $1.03(0.7-1.5)$ \\
\hline
\end{tabular}

${ }^{\text {aTTal }}$ sample size: 9975

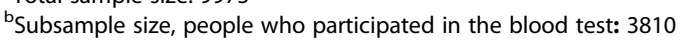

showed that $14.5 \%$ of people over 30 in Yazd province have DM [13] and in 2013, Lotfi et al., with a similar method, reported that $16 \%$ of yazd adult people have diabetes [14]. Currently, obesity in Iran is more prevalent in women than men [20] and Ghadiri et al. [21] showed that in Yazd, obesity is more prevalent in women than men. This may explain the cause of higher prevalence of T2DM among women.

The prevalence of DM has grown since 30 years ago in Iran as well as other parts of the Middle-East [22]. The lower prevalence of DM in the current study in comparison with previous studies may be due to different methods of sampling.

Zoroastrians are a religion minority in Yazd, our study showed that T2DM prevalence in this group of people is not significantly different from Muslim majority residents. Khalilzade et al. [23] in 2015 determined the prevalence of metabolic diseases in Zoroastrians and assessed DM prevalence based on FPG and Glucose Tolerance Test (GTT). They reported that total T2DM prevalence including diagnosed and undiagnosed is $26.1 \%$ among the population of older than 30 years old.

This study showed the inverse relationship between educational level and DM prevalence which is in line with other studies [24]. A low educational level can lead to harmful nutritional behaviors, obesity, lower physical activity and higher psychological stresses [25-27], all of them attributed to DM. Dray-Spira et al. reported that all-cause mortality rates in T2DM patients with lower educational levels is $28 \%$ higher than patients with higher educational level [28].

The proportion of people with T2DM who was unaware of the disease in our study was $4.8 \%$ ( $95 \% \mathrm{CI}=$ 4.1-5.5), not significantly different between male and female. In a previous study in our region [14] the prevalence of undiagnosed DM was $9.0 \%$ in total population 
and among Zoroastrians was 18.6\% [23]. In other parts of Iran, DM awareness is different. For example in Kerman- a province located south of Yazd- the prevalence of undiagnosed DM is about $2.7 \%$, however it is $25 \%$ in the north of Iran [29, 30]. Esteghamati et al. showed that DM unawareness decreased in Iran from 45 to $24 \%$ from 2005 to 2011 [22]. Considering our study, DM awareness in Yazd is more than other parts of Iran which can be attributed to information programs of the health systems involving in DM control including Diabetes Research Center that conducts health campaigns and screening programs across the province during the past decade. High prevalence of diabetes and experience of these interventions for good awareness in Yazd, can help health managers to implement action plans for prevention and control of diabetes between study periods.Overall, we found that only aging was associated with undiagnosed DM indicating that they have a higher level of DM unawareness. Also, pre-diabetes is more common in older people; irregular care over a longer period can increase undiagnosed DM, the prevalence of uncontrolled DM was approximately $60 \%$ among persons with diabetes. This poor control is consistent with other Middle Eastern studies [31]. Socioeconomic factors such as education, employment, and health insurance did not influence controlling the disease, different from other studies [32, 33].

Our result showed that $19.3 \%$ of DM patients in our region are on insulin and the rest of patients receive oral antidiabetic agents (OAD) or diet or both. Prospective data analysis from the registry of out-patient universityaffiliated clinics (NPPCD 2016) in Iran showed that more than $36 \%$ of patients with DM are on insulin or a combination of insulin and OAD [7]. However, the difference may be secondary to case collection. Our study is a community-based analysis from patients with diabetes, while the NPPCD-2016 included patients from referral university clinics with more advanced complications and it is clear that this group of patients is, obviously not representative of all DM patients.

The strength of our study was the large representative sample size, the most important limitations of our study was that only $40 \%$ of the study participants gave blood samples despite frequent reminders. Those who gave samples were not different from the rest according to nationality, religion, and birthplace in both sexes. Health insurance and employment were not different across the two groups in women. Other socioeconomic variables (age group and education) were different in those who gave blood samples versus who does not. Nonparticipants. It seems that referring to the laboratory for sampling is an important factor in non-cooperation. Sampling at home or paying a fee for car agency fare will increase participation in the next round.

\section{Conclusion}

The current study showed a high prevalence of DM in Yazd Greater Area, of every five people over 40 years, one has diabetes mellitus. The prevalence of DM is related to socio-demographic factors which requirers attention to the role of these factors in controlling the disease. Briefly, $\mathrm{DM}$ is more common in women, insured, low educated, housewives, and people with positive family history of the disease and increases with age. Although more than 90\% of the patients were aware of their disease, their blood glucose was not controlled in half of them. Pre-diabetes and undiagnosed diabetes is higher in lower educated, older, unemployed and housewives. However, uncontrolled diabetes was not related to socioeconomic factors. In the next round, intervention is required to increase participation in the blood test and reduce self-selection. The patients need to be controlled better and their medications should be adjusted according to their FPG values. Effective strategies are needed for DM prevention and control in this population. Design and implementation of patients' registry and active follow up programs may be helpful.

\section{Abbreviations \\ ADA: American Diabetes Association; Cl: Confidence Interval; DM: Diabetes Mellitus; EMRO: Eastern Mediterranean region; FPG: fasting plasma glucose; GTT: Glucose Tolerance Test; NPPCD: National Program for Prevention and Control of Diabetes; OAD: Oral Anti Diabetic; T2DM: Type 2 Diabetes Mellitus; WHO: World Health Organization; YaHS: Yazd Health Study}

\section{Acknowledgments}

We acknowledge Yazd people for participation in the study who gave up their valuable time in the interviews and Yazd Central Health workers and managers for their help and support.

\section{Authors' contributions}

The conception of research idea was conducted by Mohen Mirzaei(MM1) and Masoud Mirzaei(MM2) designed the study.Conducted the study under the supervision of MM1. MM2, MR, and MM1 analyzed the data and wrote the draught of the manuscript. AN and ADT reviewed and critically revised the manuscript. All authors read and approved the final manuscript. MM2 finalized the manuscript.

\section{Funding}

This study was funded by Shahid Sadoughi University of Medical Sciences. Funding bodies had no role in data collection, analysis, and interpretation of data and in writing the manuscript.

\section{Availability of data and materials}

The data collected by Yazd Health Study are not open access but can be shared under conditions of collaboration and endowment. Data are available from the authors upon reasonable request and with permission of principal investigator. For further information, please visit YaHS website at www.yahs.ir $/$ yahs.ssu.ac.ir

\section{Ethics approval and consent to participate}

All procedures performed in this study were approved by the ethics committee of Shahid Sadoughi University of Medical Science, Yazd, Iran (IR.SSU.MEDICINE.REC.1396.311). During the training of interviewers, principal investigator emphasis was placed on the importance of obtaining informed consent that informed that participants can choose not to answer any questions. Written informed consent was obtained from all participants.

Consent for publication

Not applicable. 


\section{Competing interests}

The authors declare that they have no competing interests.

\begin{abstract}
Author details
${ }^{1}$ Yazd Cardiovascular Research Center, Shahid Sadoughi University of Medical Sciences, Jomhuri Blvd., Afshar Hospital, Yazd, Iran. ${ }^{2}$ Yazd Diabetes Research Centre, Shahid Sadoughi University of Medical Sciences, Yazd, Iran. ${ }^{3}$ Nutrition and Food Security Research Center, Department of Nutrition, School of Public Health, Shahid Sadoughi University of Medical Sciences, Yazd, Iran. ${ }^{4}$ Department of Health Education and Promotion, Shahid Sadoughi University of Medical Sciences, Yazd, Iran.
\end{abstract}

Received: 22 September 2019 Accepted: 23 January 2020 Published online: 03 February 2020

\section{References}

1. DeFronzo RA, Ferrannini E, Groop L, Henry RR, Herman WH, Holst JJ, et al. Type 2 diabetes mellitus. Nat Rev Dis Primers. 2015;1:15019. https://doi.org/ 10.1038/nrdp.2015.19.

2. Organization WH. Global report on diabetes in 2016. Geneva: WHO. World Health Organization http://apps.whoint/iris/bitstream/10665/204871/1/ 9789241565257_eng.pdf; 2016.

3. Al-Lawati JA. Diabetes mellitus: a local and global public health emergency! Oman Med J. 2017:32(3):177-9. https://doi.org/10.5001/omj.2017.34.

4. Lozano R, Naghavi M, Foreman K, Lim S, Shibuya K, Aboyans V, et al. Global and regional mortality from 235 causes of death for 20 age groups in 1990 and 2010: a systematic analysis for the global burden of disease study 2010 Lancet. 2012;380(9859):2095-128. https://doi.org/10.1016/S01406736(12)61728-0.

5. Zhang N, Yang X, Zhu X, Zhao B, Huang T, Ji Q. Type 2 diabetes mellitus unawareness, prevalence, trends, and risk factors: National Health and nutrition examination survey (NHANES) 1999-2010. J Int Med Res. 2017; 45(2):594-609. https://doi.org/10.1177/0300060517693178.

6. Haghdoost A, Rezazadeh Kermani M, Sadghirad B, Baradaran H. Prevalence of type 2 diabetes in the Islamic Republic of Iran: systematic review and meta-analysis. East Mediterr Health J. 2009;15(3):591-9.

7. Esteghamati A, Larijani B, Aghajani MH, Ghaemi F, Kermanchi J, Shahrami A et al. Diabetes in Iran: prospective analysis from first Nationwide diabetes report of National Program for prevention and control of diabetes (NPPCD2016). Sci Rep. 2017;7(1):13461. https://doi.org/10.1038/s41598-017-13379-z.

8. Hadaegh F, Bozorgmanesh MR, Ghasemi A, Harati H, Saadat N, Azizi F. High prevalence of undiagnosed diabetes and abnormal glucose tolerance in the Iranian urban population: Tehran lipid and glucose study. BMC Public Health. 2008:8(1):176. https://doi.org/10.1186/1471-2458-8-176.

9. Mansour AA, Al-Malik AA, Kasem B, Jabar A, Mosbeh KA. Prevalence of diagnosed and undiagnosed diabetes mellitus in adults aged 19 years and older in Basrah, Iraq. Diab Metab Syndrome Obes: Targets Therapy. 2014;7: 139-44. https://doi.org/10.2147/DMSO.S59652.

10. Beagley J, Guariguata L, Weil C, Motala AA. Global estimates of undiagnosed diabetes in adults. Diabetes Res Clin Pract. 2014;103(2):150-60. https://doi. org/10.1016/j.diabres.2013.11.001.

11. Dall TM, Yang W, Halder P, Pang B, Massoudi M, Wintfeld N, et al. The economic burden of elevated blood glucose levels in 2012: diagnosed and undiagnosed diabetes, gestational diabetes mellitus, and prediabetes. Diabetes Care. 2014;37(12):3172-9. https://doi.org/10.2337/dc14-1036.

12. Sheikhpour $R$, Jalali-KhanAbadi B, Yaghmaei $P$, Salmani M, Afkhami AM. The effect of zinc supplementation on glycosylated hemoglobin in type II diabetic patients. J Shahrekord Univ Med Sci. 2011:12:58-63.

13. Afkhami-Ardekani M, Vahidi S, Vahidi A, Ahmadieh M. The prevalence of type 2 diabetes mellitus at the age of 30 years and above in Yazd province (Iranian population). J Shahid Sadoughi Univ Med Sci. 2001;9(1):22-7.

14. Lotfi MH, Saadati H, Afzali M. Prevalence of diabetes in people aged $\geq 30$ years: the results of the screening program of Yazd Province, Iran, in 2012. J Res Health Sci. 2013;14(1):88-92.

15. Katibeh M, Hosseini S, Soleimanizad R, Manaviat M, Kheiri B, Khabazkhoob $M$, et al. Prevalence and risk factors of diabetes mellitus in a central district in the Islamic Republic of Iran: a population-based study on adults aged 4080 years. East Mediterr Health J. 2015;21(6):412.

16. Mirzaei MS-AA, Mirzaei M, Mohsenpour MA. The Yazd Health Study (YaHS): a population-based study of adults aged 20-70 years ( study design and baseline population data). Int J Epidemiol. 2018;47(3):697-698h. https://doi org/10.1093/ije/dyx231.

17. Yue J, Mao X, Xu K, Lü L, Liu S, Chen F, et al. Prevalence, awareness, treatment and control of diabetes mellitus in a Chinese population. PLoS One. 2016;11(4):e0153791.

18. Kim C-H, Kim H-K, Kim E-H, Bae S-J, Choe J, Park J-Y. Risk of progression to diabetes from prediabetes defined by $\mathrm{HbA} 1 \mathrm{c}$ or fasting plasma glucose criteria in Koreans. Diabetes Res Clin Pract. 2016;118:105-11. https://doi.org/ 10.1016/j.diabres.2016.06.009

19. Rosella LC, Lebenbaum M, Fitzpatrick T, Zuk A, Booth GL. Prevalence of prediabetes and undiagnosed diabetes in Canada (2007-2011) according to fasting plasma glucose and HbA1c screening criteria. Diabetes Care. 2015; 38(7):1299-305. https://doi.org/10.2337/dc14-2474.

20. Moghimi-Dehkordi B, Safaee A, Vahedi M, Pourhoseingholi A, Pourhoseingholi M, Ashtari S, et al. Overweight and obesity and related factors in urban Iranian population aged between 20 to 84 years. Ann Med Health Sci Res. 2013;3(2):171-6. https://doi.org/10.4103/2141-9248.113656.

21. Ghadiri-Anari A, Jafarizadah M, Zare A, Mozaffari-Khosravi H, Afkhami-Ardekani M, Shojaoddiny-Ardekani A. Prevalence of obesity and overweight among adults in Iranian population (Yazd Province). Iran J Diab Obes. 2013;5(2):67-70.

22. Esteghamati A, Etemad K, Koohpayehzadeh J, Abbasi M, Meysamie A, Noshad S, et al. Trends in the prevalence of diabetes and impaired fasting glucose in association with obesity in Iran: 2005-2011. Diabetes Res Clin Pract. 2014;103(2):319-27. https://doi.org/10.1016/j.diabres.2013.12.034.

23. Khalilzadeh S, Afkhami-Ardekani M, Afrand M. High prevalence of type 2 diabetes and pre-diabetes in adult Zoroastrians in Yazd, Iran: a crosssectional study. Electron Physician. 2015;7(1):998-1004. https://doi.org/10. 14661/2015.998-1004

24. Sacerdote C, Ricceri F, Rolandsson O, Baldi I, Chirlaque M-D, Feskens E, et al. Lower educational level is a predictor of incident type 2 diabetes in European countries: the EPIC-InterAct study. Int J Epidemiol. 2012:41(4): 1162-73. https://doi.org/10.1093/ije/dys091.

25. Veghari G, Sedaghat M, Maghsodlo S, Banihashem S, Moharloei P, Angizeh A, et al. The correlation between educational levels and central obesity in the north of Iran: an epidemiologic study. ARYA Atherosclerosis. 2013:9(4):217-22.

26. Hajian-Tilaki K, Heidari B. Prevalence of obesity, central obesity and the associated factors in the urban population aged 20-70 years, in the north of Iran: a population-based study and regression approach. Obes Rev. 2007; 8(1):3-10. https://doi.org/10.1111/j.1467-789X.2006.00235.x.

27. Maddah M, Eshraghian M, Djazayery A, Mirdamadi R. Association of body mass index with educational level in Iranian men and women. Eur J Clin Nutr. 2003:57(7):819-23. https://doi.org/10.1038/sj.ejcn.1601615.

28. Dray-Spira R, Gary-Webb TL, Brancati FL. Educational disparities in mortality among adults with diabetes in the US. Diabetes Care. 2010;33(6):1200-5. https://doi.org/10.2337/dc09-2094.

29. Najafipour H, Sanjari M, Shokoohi M, Haghdoost AA, Afshari M, Shadkam M, et al. Epidemiology of diabetes mellitus, pre-diabetes, undiagnosed and uncontrolled diabetes and its predictors in general population aged 15 to 75 years: a community-based study (KERCADRS) in southeastern Iran. J Diabetes. 2015;7(5):613-21. https://doi.org/10.1111/1753-0407.12195.

30. Veghari G, Sedaghat M, Joshaghani H, Hoseini SA, Niknezad F, Angizeh A, et al. Association between socio-demographic factors and diabetes mellitus in the north of Iran: a population-based study. Int J Diab Mellitus. 2010;2(3): 154-7. https://doi.org/10.1016/j.ijdm.2010.09.001.

31. Alzaheb RA, Altemani AH. The prevalence and determinants of poor glycemic control among adults with type 2 diabetes mellitus in Saudi Arabia. Diab Metab Syndr Obes. 2018;11:15-21. https://doi.org/10.2147/ DMSO.S156214

32. Assari S, Moghani Lankarani M, Piette JD, Aikens JE. Socioeconomic status and glycemic control in type 2 diabetes; race by gender differences. Healthcare (Basel). 2017:5(4):83. https://doi.org/10.3390/healthcare5040083.

33. Esteghamati A, Larijani B, Aghajani MH, Ghaemi F, Kermanchi J, Shahrami A, Saadat M, Esfahani EN, Ganji M, Noshad S, Khajeh E, Ghajar A, Heidari B, Afarideh M, Mechanick Jl, Ismail-Beigi F. Diabetes in Iran: prospective analysis from first Nationwide diabetes report of National Program for prevention and control of diabetes (NPPCD-2016). Sci Rep. 2017;7(1):13461. https://doi.org/10.1038/s41598-017-13379-z.

\section{Publisher's Note}

Springer Nature remains neutral with regard to jurisdictional claims in published maps and institutional affiliations. 